Article

\title{
On the Acceptability of Electricity Demand Side Management by Time of Day
}

\author{
Satoshi Nakano ${ }^{1}$ (I) and Ayu Washizu ${ }^{2, *}$ \\ 1 Faculty of Economics, Nihon Fukushi University, Aichi 477-0031, Japan; nakano@n-fukushi.ac.jp \\ 2 Faculty of Social Sciences, Waseda University, Tokyo 169-8050, Japan \\ * Correspondence: washizu@waseda.jp
}

Received: 29 June 2020; Accepted: 13 July 2020; Published: 16 July 2020

\begin{abstract}
Advances in the introduction of fluctuating renewable energies, such as photovoltaics (PV), have caused power-system destabilization. However, stability can be improved if consumers change the way they use power, moving to time slots when the PV output in an area is high. In large cities in developed countries, where the types of distributed energy resources are varied, demand side management (DSM) in which consumers share power supplies and adjust the demand has received considerable attention. Under effective DSM that uses the latest information and communication technology to maximize the use of renewable energy, we believe that sparing use of appliances is not the only solution to address global warming. If behavioral change shifts the use of domestic appliances from one time slot to other time slots, we do not have to abandon the use of these appliances. The aim of this study is to determine the possibility of such behavioral changes in people in order to provide basic information for operating an effective DSM. To that end, we conducted a questionnaire-based survey of 10,000 households in Japan. We investigated the proportion of people responding to a request for a demand response (DR) under the given presented reward in time slots when DSM by DR is required. We also analyzed the factors influencing people's response to a request for a DR. Furthermore, based on the rewards likely to be achieved in the adjustable power market, we estimated how much adjustable power would be realized.
\end{abstract}

Keywords: demand side management; demand response; random utility model; consumer behavior; prosumer

\section{Introduction}

The number of homes with rooftop solar panels (photovoltaic (PV) devices) in Japan has rapidly increased from 0.28 million in 2003 to 2.19 million in 2018 [1]. Simultaneously, distributed energy resources (DERs), such as domestic-sized batteries, electric vehicles (EVs), and domestic heat pump water heaters, have become popular in residential areas. The number of domestic-scale lithium-ion storage battery systems shipped in Japan increased from 1939 units in FY2011 to 73,594 units in FY2018 [2]. The composition ratio of EVs (including plug-in hybrid vehicles) will increase to $20-30 \%$ of all vehicles by 2030 [2]. Domestic heat pump water heaters, first commercialized in 2001, cumulatively amounted to 6.39 million units by FY2018 [3]. These DERs transformed end users of electricity into prosumers. Prosumers are consumers who benefit from electricity trading by generating electricity or creating electricity demand using their own devices. To increase the reliability of both electric utilities and prosumers, energy management technology is rapidly progressing to connect these DERs using information and communication technology (i.e., Internet of Things (IoT)) [4].

Recently in Japan, PV output fluctuations have destabilized the power system. If prosumers shift power consumption to time slots when the PV output in the area is excessive, they can contribute to the improved stability of the power system. Demand response (DR) means that a prosumer takes 
such an action in exchange for a certain reward in response to a request from the electric utility that manages the stability of the power grid [5].

There are two types of DR: "down DR", which reduces (suppresses) power demand, and "up DR", which increases (creates) demand for electric utilities. Down DR entails discontinuing the use of electrical equipment and refraining from using electricity at peak demand time. Up DR refers to the consumption of electricity by domestic appliances, heat pump water heaters, or charging domestic-sized batteries when the PV output in the area is excessive. Technological development for demand side management (DSM) utilizing the IoT is rapidly advancing for the purpose of socially optimizing these actions.

To confirm the social effectiveness of DSM, Nakano and Washizu [6] calculated the potential for adjusting electricity usage in line with DR, according to the behavioral change of consumers at different time slots, using the National Survey on Time Use and Leisure Activities (STU). STU is a public statistical survey conducted by the Ministry of Internal Affairs and Communications (MIC) of Japan, which shows the daily behavioral patterns of people with various attributes every $15 \mathrm{~min}$. Using STU, Nakano and Washizu [6] calculated the adjustable electricity usage assumed for each 15 min period as follows: For example, suppose a person with a certain attribute cleans house for a certain $15 \mathrm{~min}$ period of the day. In that case, assuming that the person was using a vacuum cleaner for $15 \mathrm{~min}$, Nakano and Washizu [6] calculated the adjustable electricity that the person could create by not cleaning during that $15 \mathrm{~min}$ period. The adjustable electricity for each time slot is calculated by summing the adjustable electricity for each $15 \mathrm{~min}$, of people with each attribute, weighted by the proportion of the demographic composition by attribute. (In addition to calculating the potential power savings for each $15 \mathrm{~min}$ period of people using domestic appliances, Nakano and Washizu [6] also calculated the potential power savings in each $15 \mathrm{~min}$ period when old domestic appliances are replaced with energy-saving ones and when using domestic appliances with more energy-saving behavior. In this research, we focused on the calculation result when the use of domestic appliances was stopped. This result was chosen because it is equal to the amount of electricity used by domestic appliances and is considered to be the maximum amount of electricity that can be adjusted during that time slot.) As a result, it was confirmed that the potential electricity usage, which can be adjusted by behavioral changes, helps mitigate constrained electricity supply in the event of a disaster. This indicates that promoting behavioral changes in people through DR may be useful for a stable electricity supply. The STU is a national statistical survey conducted on a large scale based on a sample design that considers the population composition of the whole country. Analytical results based on the STU have high accuracy. However, because there were no survey data on the proportion of people who responded to electricity adjustment every $15 \mathrm{~min}$, Nakano and Washizu [6] only provided speculative results for this point.

Under effective DSM that uses the latest IoT to maximize the use of renewable energy, we believe that sparing use of appliances is not the only solution to address global warming. If behavioral change shifts the use of domestic appliances from down-DR time slots to up-DR time slots, we do not have to abandon the use of these appliances. The aim of this study is to determine the realistic possibility of such behavioral changes in prosumers in order to provide basic information for operating an effective DSM. In this study, we conducted a survey, using a questionnaire, of approximately 10,000 households in Japan and investigated what percentage of people are likely to respond to a request for a DR in each time slot when DSM, using DR, is required. Furthermore, we analyzed the factors affecting people's responses to a request for a DR. These results were applied to the adjustable potential electricity via the DSM calculated by Nakano and Washizu [6]. Then, we estimated the amount of adjustable electricity that could be realized under the given reward for responding to a request for a DR.

This paper is structured as follows: In Section 2, previous studies on factors influencing people's participation in DSM and the effects of these factors are discussed. Section 3 describes our survey outline, and Section 4 describes the aggregation method and our analysis of the survey results. Section 5 summarizes the results of analysis; based on this, the probability of a response to a request for a DR 
under the given presented reward is estimated in Section 6. Section 7 discusses the significance of measuring the potential of DSM from a macroscopic perspective, which is particularly important in large cities in developed countries. Lastly, Section 8 summarizes the paper.

\section{Literature}

Since public, in other words, prosumer, participation is a key factor determining the effectiveness of a new sustainable energy system including DSM, the conditions of public participation are actively being studied. Using sociological methods, Büscher and Sumpf [7] showed that trust and confidence in new systems create mechanisms to reduce complexity, leading to improved public participation behavior. Improving areas of the new system where public trust and confidence are lacking would also improve public participation. Soland et al. [8] showed that the problem of social acceptance arises because DSM tends to interfere with the autonomy and privacy of individuals. Through a psychology focus group study in Switzerland, they revealed that there is no single solution, due to the diversity of consumers, and that transparent communication and trust are important. Using the consumer profiling method, He et al. [9] analyzed various consumers from two perspectives and considered DR contract types suitable for the various consumers. The two perspectives were the consumer's technical abilities and preferences on high-level terms of DR contracts. Stenner et al. [10] pointed out that distrust in Australian utilities weakens users' willingness to participate in DSM through their survey experiment conducted from a behavioral economic perspective. Good [11] also analyzed the influence of consumer bias and preferences on DR from the perspective of behavioral economics, incorporating psychology, by expanding the existing techno-economic model. As a result, he pointed out that DR can be solicited without increasing system cost by appealing to consumers' prosocial preferences. Through a demonstration experiment in the USA, Pratt et al. [12] showed that a prosocial impulse, such as a donation by the distribution company to a charity when power consumption decreases during peak hours, can reduce peak power consumption by $13.5 \%$. Siebert et al. [13] also developed a computer simulation model in the framework of behavioral economics and simulated various consumer heuristics that could affect power consumption.

In summary, the factors that influence people's acceptance of DSM have been studied using experimental approaches. Many studies have shown trust in utility suppliers to be a positive factor influencing the acceptance of DSM. Certain studies have also revealed that people's technical comprehension and prosocial preferences play an important role.

Some studies have empirically, not experimentally, explored the factors that influence people's acceptance of the DSM. Iliopoulos et al. [14] analyzed the results of a survey of 207 low-income households in Japan using a social psychology method. According to Iliopoulos et al. [14], the low income and willingness to reduce energy consumption expenditure are correlated, but the fear of perceived additional cost required to implement equipment for DSM hinders acceptance. Users of smart technologies for DSM consider their utility companies to have a better reputation than those who do not. Their conclusion that trust increases technology acceptance while technology acceptance increases trust offers insight into DSM. Washizu et al. [15] compared the results of questionnaire surveys conducted in Japan and the United States regarding people's willingness to accept a home energy management system (HEMS) as a piece of indispensable equipment for home DSM. They showed that Japanese households are more sensitive to HEMS operating costs and that familiarity with HEMS in Japan and trust in utility companies in the United States increased people's willingness to accept HEMS. These two previous studies show that, in addition to trust in utility companies, experience and familiarity with smart technology that supports DSM affects people's willingness to accept the DSM. In addition, Washizu et al. [15] suggest that operation costs greatly affect people's willingness to participate in DSM, especially in Japan. Based on a questionnaire survey in Germany, Roth et al. [16] empirically demonstrated that co-ownership of renewable energy facilities has a positive correlation with people's cooperative DSM behavior by increasing the knowledge and awareness of participants. 
Even in these empirical studies, trust in utility companies and knowledge of new technologies were confirmed to be factors affecting people's acceptance of DSM. Certain empirical studies have also shown that anxiety regarding cost affects the acceptance of DSM. In the aforementioned experimental or empirical studies, DSM was positioned as a means to enable maximum use of renewable energy, and people's cooperation with DSM was almost equal to environmentally conscious behavior.

However, Walzberg et al. [17] pointed out that the time consideration factor is indispensable for evaluation of the environmental impact of DSM. In other words, accepting DSM does not always have a positive effect on the environment; only DSM that is bound to time considerations can have a positive effect on it. Ruokamo et al. [18] analyzed Finnish households' willingness to accept DSM by incorporating the time factor. They conducted a choice experiment and analyzed the willingness of households to incorporate flexibility in the timing of power consumption. According to their results, the households required considerable compensation, although they recognized the environmental value of DSM. In the choice experiment conducted by Sundt et al. [19] in Germany, and the demonstration experiment conducted by Nilsson et al. [20] in Sweden, people changed their behavior to reduce power consumption during peak hours, using time-of-use (TOU) electricity tariffs as an indicator. In fact, the feasibility of DSM in the sense of shifting power usage time slots was confirmed. In addition, Khalilpour and Lusis [21] showed that imposing a high price on peak users of electricity will promote the spread of devices that are DSM objectives, such as distributed power sources and storage batteries. In addition, the results of some demonstration experiments showed that providing information through in-home displays or e-mails is effective for shifting people's peak behavior [22,23].

In summary, attempts to get people to respond to DSM at desired times through hourly electricity charges, although they have some effect, sometimes require high compensation or costly information provision.

Under such circumstances, there are some studies that consider the mechanisms of DSM that make it easier for people to respond by understanding differences in the behavior of people by time of day. Ahmed et al. [24] pointed out that a control framework driven by people's behavior patterns is necessary to improve the effectiveness of DSM, and they developed a new control system for the home. This may also apply to social system design (for example, building a TOU fee system and selecting information to be transmitted to consumers). Walzberg et al. [25] said that designing a TOU electricity tariff system that does not consider household behavior may have a negative effect on the environment.

Bottom-up models for domestic energy demand forecasting have been developed by incorporating lifestyle behaviors that largely depend on uncertain human factors into the models using a stochastic approach [26-29]. Using such household power demand models, Aryandoust and Lilliestam [26] examined how to effectively use DSM in Germany, Fischer et al. [27] pointed out that a customer-specific pricing system is as desirable as possible, and Thiaux et al. [28] showed that DSM can help reduce energy costs and improve solar power utilization in a microgrid. Nijhuis et al. [29] set the parameters of a stochastic model that describes the lifestyle behavior of a household based on the STU. Their model reproduced the electricity demands of real households successfully. Torriti [30], López-Rodríguez et al. [31], and Santiago et al. [32] used the results of STU in fifteen EU countries and Spain as parameters for a stochastic model that reproduced uncertain household lifestyle behavior. While they did not predict power demand (except for television power consumption), they concluded that lifestyle behavior prediction was essential for effective DSM implementation. The bottom-up model is used to analyze trends in household energy demand by time of day or trends in power demand changes caused by shifts in exogenous conditions.

On the other hand, Nakano and Washizu [6] used STU to estimate the potential amount of DSM by time of day, which is inherent in household behavior in Japanese society. Nakano and Washizu [6] estimated the amount of electricity socially adjusted by DSM and confirmed that it was sufficient to help alleviate the electricity supply/demand pressure in society. Conceptually, their estimation results should be the same as the weighted sum of individual bottom-up models using population data. However, for the purpose of confirming the quantitative effectiveness of DSM at the macrolevel, 
the behavior of individual households' electricity demand by time slot is unnecessary information. Instead, Nakano and Washizu [6] calculated the electricity demand of collective households by time slot. The macroscopic approach used by Nakano and Washizu [6] was also considered important in verifying the ultimate accuracy of the microscopic bottom-up model. Nakano and Washizu [6] understood the behavior of people by time of day from a macroscopic point of view and tried to find evidence that would contribute to the construction of a DSM (with time perspective) system that is easy for people to respond to.

As mentioned in the previous section, one solution with which to address global warming could come from an increase in the rate at which renewable energy is utilized owing to a change in people's behavior via DSM. The purpose of this study is to determine the potential efficacy of DSM through improving the estimation accuracy of the amount of electricity socially adjusted via the DSM shown by Nakano and Washizu [6] by adding the survey results of people's response rate to the DSM. We also examine the effects of factors often considered in previous studies, such as people's familiarity with new technologies and prosocial preferences, on the response rate to DSM and adjustable electricity.

\section{Survey Outline}

A survey company (Nikkei Research Inc.) was commissioned to conduct the survey online from 31 May to 5 June 2019. The survey targets were Japanese men and women aged 20-79, who usually undertake housework; these targets were registered with the survey company. Based on the 2015 Population Census, the survey targets were categorized according to age and household type, according to the composition ratio in Table 1 . The number of collected samples was 10,881.

Table 1. Composition ratio of sample based on 2015 Population Census.

\begin{tabular}{ccccccc}
\hline Age & $\begin{array}{c}\text { Single } \\
\text { (Male) }\end{array}$ & $\begin{array}{c}\text { Single } \\
\text { (Female) }\end{array}$ & Couple & $\begin{array}{c}\text { Couple with } \\
\text { Children }\end{array}$ & $\begin{array}{c}\text { Single Parent } \\
\text { with Children }\end{array}$ & $\begin{array}{c}\text { Three } \\
\text { Generations }\end{array}$ \\
\hline$\leq 39$ & $7.7 \%$ & $4.9 \%$ & $2.4 \%$ & $6.9 \%$ & $1.1 \%$ & $0.2 \%$ \\
\hline $40-64$ & $7.8 \%$ & $4.5 \%$ & $6.8 \%$ & $16.6 \%$ & $4.6 \%$ & $1.7 \%$ \\
\hline$\geq 65$ & $4.2 \%$ & $8.6 \%$ & $12.9 \%$ & $5.9 \%$ & $2.6 \%$ & $0.6 \%$ \\
\hline Total & $19.7 \%$ & $18.1 \%$ & $22.0 \%$ & $29.3 \%$ & $8.3 \%$ & $2.5 \%$ \\
\hline
\end{tabular}

In the survey, we asked if the respondents would respond to a request for a DR by shifting their activity time slots when down or up DR is requested, along with the amount of reward they would like to receive. Figure 1 shows the flow of the questions.

The activities we surveyed were cleaning, meal preparation, washing, and watching TV. According to Nakano and Washizu [6], these activities provide significant adjustable potential electricity for DR during certain time slots of the day. First, we divided a day into 12 time slots: 0:00-2:00, ... , 22:00-24:00. We then questioned the respondents regarding the time slot in which they usually perform these activities (Question $1(\mathrm{Q} 1)$ ). Next, we asked whether the respondents could shift the time slot in which a target activity is currently performed to another time slot and asked the respondents to select one of the following options: I may shift my time slot (1) unconditionally, (2) with a reward of 1-99 JPY per month, ... , (8) with a reward of 1000 JPY or more per month, (9) I may not shift my time slot regardless of the amount of reward (Question 2 (Q2)). Furthermore, we asked those who selected responses 1-8 to the previous question to specify the time slots to which they could shift the current activity time slots (Question $3(\mathrm{Q} 3)$ ). 


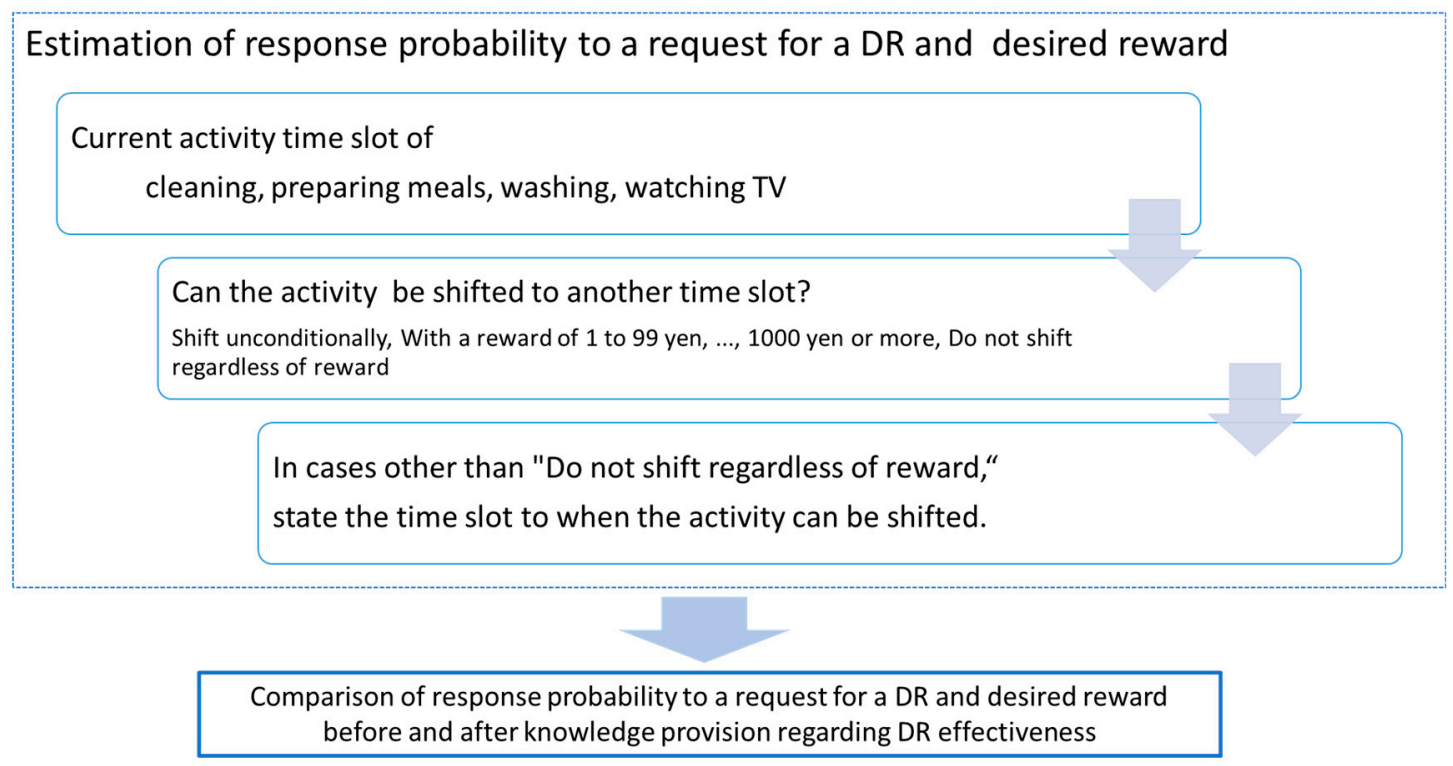

Figure 1. Flow of questions, where DR stands for demand response.

We asked these questions without commenting on the social effectiveness of their time shift of activities in response to DR. Respondents may change their behavior if they have knowledge about the social effectiveness of the time shift. Several previous studies have also pointed out that prosocial preferences promote people's participation in DSM. After giving the following explanation, we repeated Q2 and Q3: "If many households cooperate to shift their usage time of home appliances during the time when electricity consumption in Japan increases significantly, the operation of a critical thermal power plant may be stopped. As a result, social energy costs and $\mathrm{CO}_{2}$ emissions may be reduced." In addition, we investigated the demographic attributes of respondents, their usage status of personal computers and smartphones, and energy-saving consciousness as factors that may influence these answers.

\section{Analytical Method}

\subsection{Basic Aggregation}

We calculated, for each of the 12 time slots $(0: 00-2: 00, \ldots, 22: 00-24: 00)$, the action probability of cleaning, meal preparation, washing, and watching TV (ratio of number of respondents who perform each activity in each time slot to number of respondents, excluding respondents who do not usually do the activity from the entire sample). Then, for each activity of cleaning, preparing meals, washing, and watching TV, we aggregated the number of respondents who may shift their usual time slot of each activity according to the following options: I may shift my time slot (1) unconditionally, (2) with a reward of 1-99 JPY per month, ..., (8) with a reward of 1000 JPY or more per month, (9) I may not shift my time slot regardless of the amount of reward. Data were collected from six types of households (single male, single female, couple, couple with children, single parent with children, and three generations) and for the entire sample.

\subsection{Assumption of the DR Activation Time Slot}

One of the purposes of this study is to estimate the rate of response to a request for a DR. This section describes the basis for the assumed time slots in which the DR is triggered. As mentioned in Section 1, there are two types of DR: "down DR", which reduces (suppresses) electricity demand from the power network, and "up DR", which increases (creates) demand for electricity. Down DR is effectively activated during times when the electricity demand is extremely high in the year. Successful down DR at such times can avoid the construction and operation of thermal power plants that are idle 
for most of the year and operate only in such cases. Each power transmission and distribution company publishes electricity supply and demand records for each time slot in its service area, based on business guidelines for power transmission and distribution issued by the Organization for Cross-regional Coordination of Transmission Operators, Japan (OCCTO). According to the records, the demand for electricity is extremely high during the daytime in midsummer and in the mornings and evenings during midwinter. Up DR is effectively activated when there is surplus photovoltaic power at times when electricity demand is relatively low. In Japan, surplus photovoltaic power has become apparent within the jurisdiction of the Kyushu Electric Power Company (an electric power company that has jurisdiction over the southern region of Japan); in fact, instructions have been issued to suppress the output of photovoltaic power. The time slot in Kyushu when such instructions are issued is during spring and autumn daytime, when demand for electricity for heating and cooling is low.

In this study, based on these circumstances, we assumed that the time slots during which DR was activated were 8:00-16:00 in summer, 6:00-10:00 and 16:00-22:00 in winter, and 10:00-14:00 in spring/autumn. According to the report of OCCTO or Kyushu Electric Power Company, DR is considered effective in these time slots. In addition, this DR time slot definition is consistent with the 2-h intervals used in the questionnaire. In the next section, we estimated the responsiveness of respondents to a request for a DR under these assumptions.

\subsection{Number of Respondents Who Can Respond to a Request for a DR by Presented Reward}

We questioned the respondents regarding the time slot when they usually carried out activities such as cleaning, meal preparation, washing, and watching TV. We also asked the respondents about the time slots when they could shift their current activity and the amount of reward they would like to receive at that time.

Using these response results, the number of respondents who "can respond" to a request for a DR in summer, winter, and spring/autumn was aggregated for each category of presented reward. Figure 2 shows the method of defining "people who can respond to a request for a DR" in this study. Suppose, for example, a respondent who is cleaning between 8:00 and 16:00 may shift his/her current cleaning time slot to another time slot under a certain amount of presented reward (category). In this case, this respondent is defined as a person who can respond to down DR in summer under the presented reward. Suppose a respondent who is cleaning at time slots excluding 10:00-14:00 may move his/her current cleaning time slot to 10:00 to 14:00 under a certain reward. At that time, this respondent is defined as a person who can respond to a request for an up DR in spring/autumn under the presented reward. In this way, the number of respondents who can respond to a request for a DR in summer, winter, and spring/autumn was aggregated for each of eight categories of presented rewards. Totals of those who can respond to a request for a DR were calculated for household types of single households (male), single households (female), couples, couples with children, single parents with children, three generations, and the entire sample.

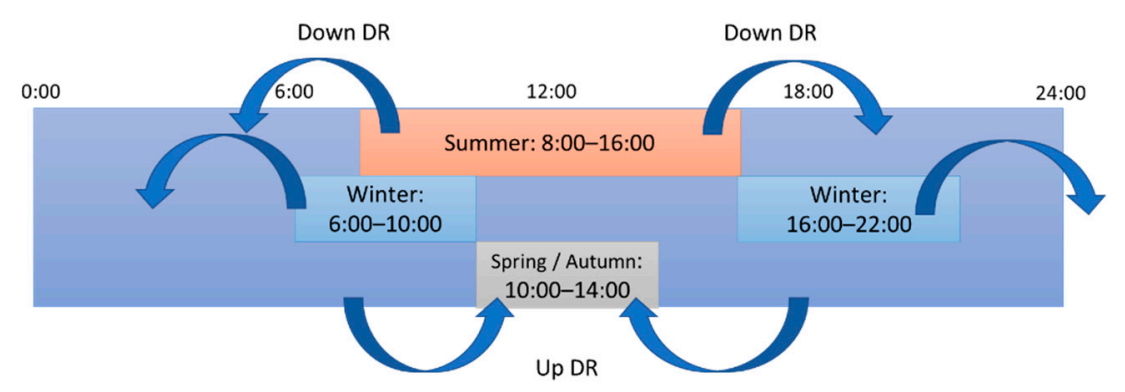

Figure 2. Assumption of DR activation time slot. Summer and winter: stop performing activities during the above time slots and move them to other time slots. Spring/autumn: have activities during other time slots moved to the above time slots. 
These datasets were created for responses before and after provision of knowledge about social effectiveness of DR.

\subsection{Estimation of Response Probability to a Request for a DR}

In the previous section, we aggregated the number of respondents who responded to a request for each DR by the category of the presented reward. Using these data, we estimated the expected response probability to a request for each DR, under the given reward. The estimation method used is the same as the method used by Washizu et al. [15]; it is outlined below.

Prior to the estimation of such a response probability to a request for a DR, we first converted one piece of data, "a respondent responds by activation of a certain DR under a certain presented reward", into a set of eight binary data by eight presented reward categories. For example, if a respondent responded to a request for a DR under the third highest presented reward category, we considered that he/she would respond to a request for a DR under the top three presented reward categories and would not respond under the fourth to eighth categories. One piece of data showing a respondent's behavior was transformed into a set of eight binary data in which 1, denoting "responds to a request for a DR", corresponds to the top three presented reward categories, and 0, denoting "does not respond", corresponds to the fourth to eighth categories.

Using a set of binomial data created in this way, we estimated the response probability to a request for a DR under a given presented reward by estimating a binomial logit model based on a well-known random utility model. That is, the probability that a respondent will respond to a request for a DR, $\mathrm{P}_{\text {yes }}$, can be expressed by the following binomial logit model [33]:

$$
\mathrm{P}_{y e s}=\frac{1}{1+e^{-\Delta V}}
$$

Here, $\Delta V$ is a utility difference function that shows the observable difference in utility when the respondent responds to a request for a DR and when he/she does not and is a function of the presented reward, $p$, for the respondent to respond to a request for a DR.

$$
\Delta V=\alpha_{1}+\beta_{1} p+u_{1}
$$

By estimating parameters $\alpha_{1}$ and $\beta_{1}$ under such a model, we can calculate the response probability to a request for a DR under a given presented reward. In this study, parameter estimation was performed for datasets before and after providing knowledge about the social effectiveness of DR. By comparing the derived response probabilities for a request for a DR before and after knowledge provision, we examined the change in response probability due to knowledge provision. We also analyzed the effect of a shift factor on the response probability by setting the utility difference function $\Delta V$ to be a function of the presented reward, $p$, and given shift term $\delta$ as in Equation (3).

$$
\Delta V=\left(\alpha_{1}+\alpha_{d} \delta\right)+\left(\beta_{1}+\beta_{d} \delta\right) p+u_{2}=\alpha_{2}+\beta_{2} p+u_{2}
$$

In this study, we assumed the respondents' responses to the following statement to be a shift factor of $\delta$ : "In order to prevent instability of the power system during the time when electricity usage increases sharply, I may shift the housework with use of home appliances performed during that time to other times." From this, we examined the effect of respondents' perceived effectiveness of DR on the response probability to a request for a DR. We believe that respondents' perceived effectiveness of DR arises from their trust in utility companies and their knowledge of advanced technology, which previous studies have often cited as factors that influence people's participation in DSM. Tables S1 and S2 present the results of the analysis conducted using the dataset for all respondents generated before and after they were provided knowledge about the social effectiveness of DR. 


\section{Results}

\subsection{Action Probability of the Four Activities in Each Time Slot}

The calculation results of the action probability of each activity such as cleaning, meal preparation, washing, and watching TV in each time slot are as follows: The action probability of cleaning was high during the time slot 8:00-10:00. Regarding meal preparation, the total average action probability in the 6:00-8:00 (at breakfast) and 16:00-20:00 (at dinner) time slots is approximately $34-50 \%$, and the average action probability in the time slot 10:00-14:00 (at lunch) was approximately 18-22\%. Regarding washing, the action probability was high in the slot 6:00-10:00, with a total average of $26-33 \%$. In addition, single-person (female) and couple households also had a peak of approximately $14-23 \%$ in the action probability at 18:00-22:00. With regard to watching TV, the action probability in the time slot 18:00-22:00 was particularly high, with a total average of $57-68 \%$.

There was no significant difference between household attributes in these trends regarding action probability.

\subsection{Respondents' Intention to Shift Their Activity Time Slots by the Presented Reward}

In Figure 3, respondents' responsiveness to shifts in activity time slots is compared by activity type. It also shows how the situation changes before and after providing knowledge about the social effectiveness of DR.

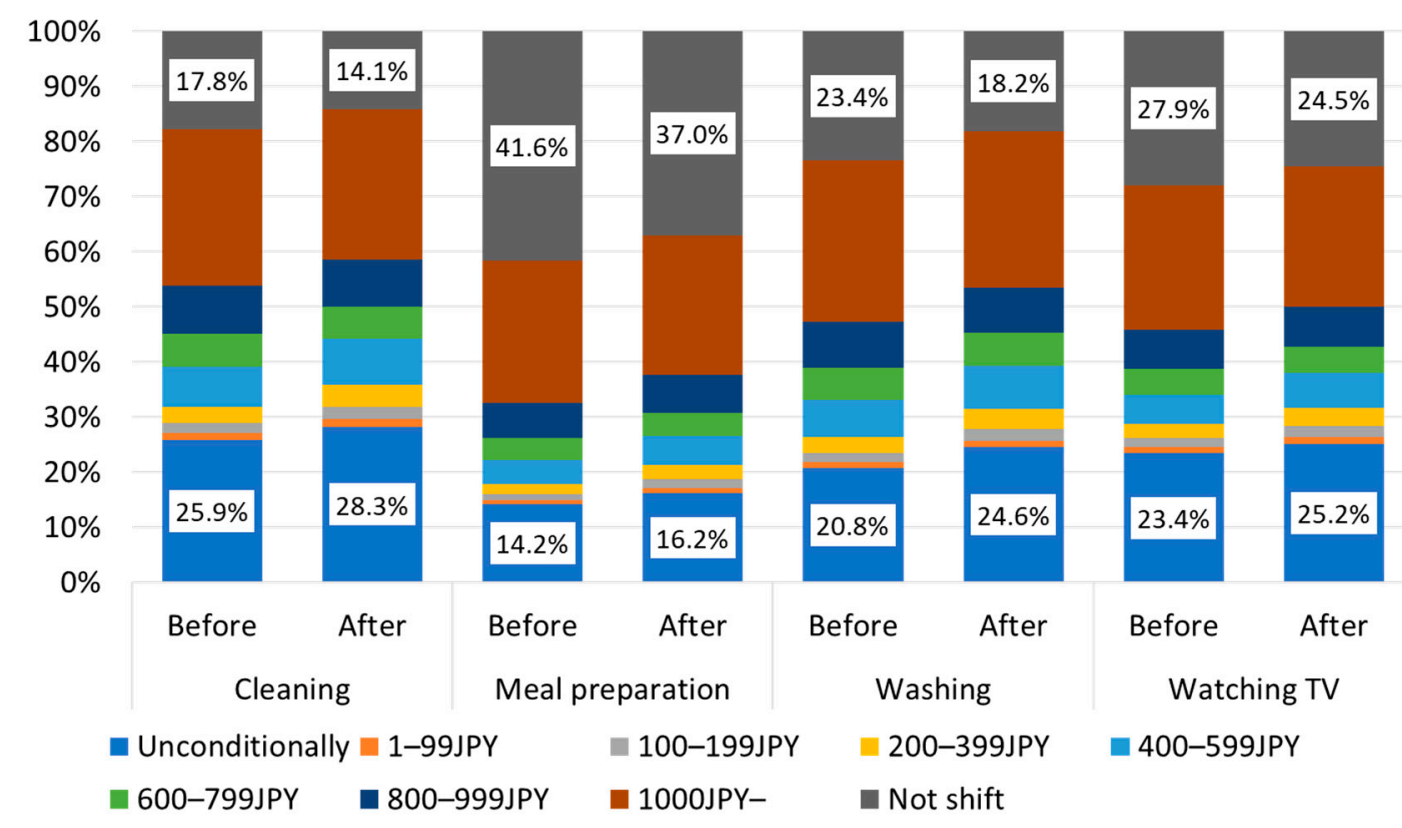

Figure 3. Changes in activity time shift intention before and after providing knowledge (all households).

Looking at the percentage of people who do not shift their current activity time slots among those who usually do each activity, a relatively large number of people (a ratio of $41.6 \%$ before the knowledge is provided) cannot shift their time slots to prepare meals. Looking at the results in detail by household attributes, the proportion of people who do not shift their current activity time slots was high among three generations for all activities. The ratio of those who were able to shift their activity time slots was relatively high in the households of couples with children, for all activities except meal preparation.

It was found that the provision of knowledge about the social effectiveness of DR reduces the proportion of respondents who cannot shift activity time slots regardless of reward for any activity, and that the percentage of people who may shift their activity time slots unconditionally (without any rewards) increased. 


\subsection{Respondents' Intention to Respond to a Request for One of Three Types of DR}

We calculated the proportion of respondents who responded to a request for each DR in summer, winter, and spring/autumn. We also compared the results before and after providing knowledge about the social effectiveness of DR. These results are shown in Figure 4. According to Figure 4, although there are differences between activities, 5-20\% of respondents who usually perform each activity respond to a request for a particular DR. The proportion of people who respond to a request for a DR is increased after knowledge is provided about the social effectiveness of DR. Another $30 \%$ of respondents who usually perform each activity can respond to some shifts in activity time slots in a manner other than the time shifts assumed in DR in this study. It is desirable to encourage these people to shift their activity time slots corresponding to down DR in summer and winter, or up DR in spring/autumn, by making them aware of how to effectively shift their activity time.

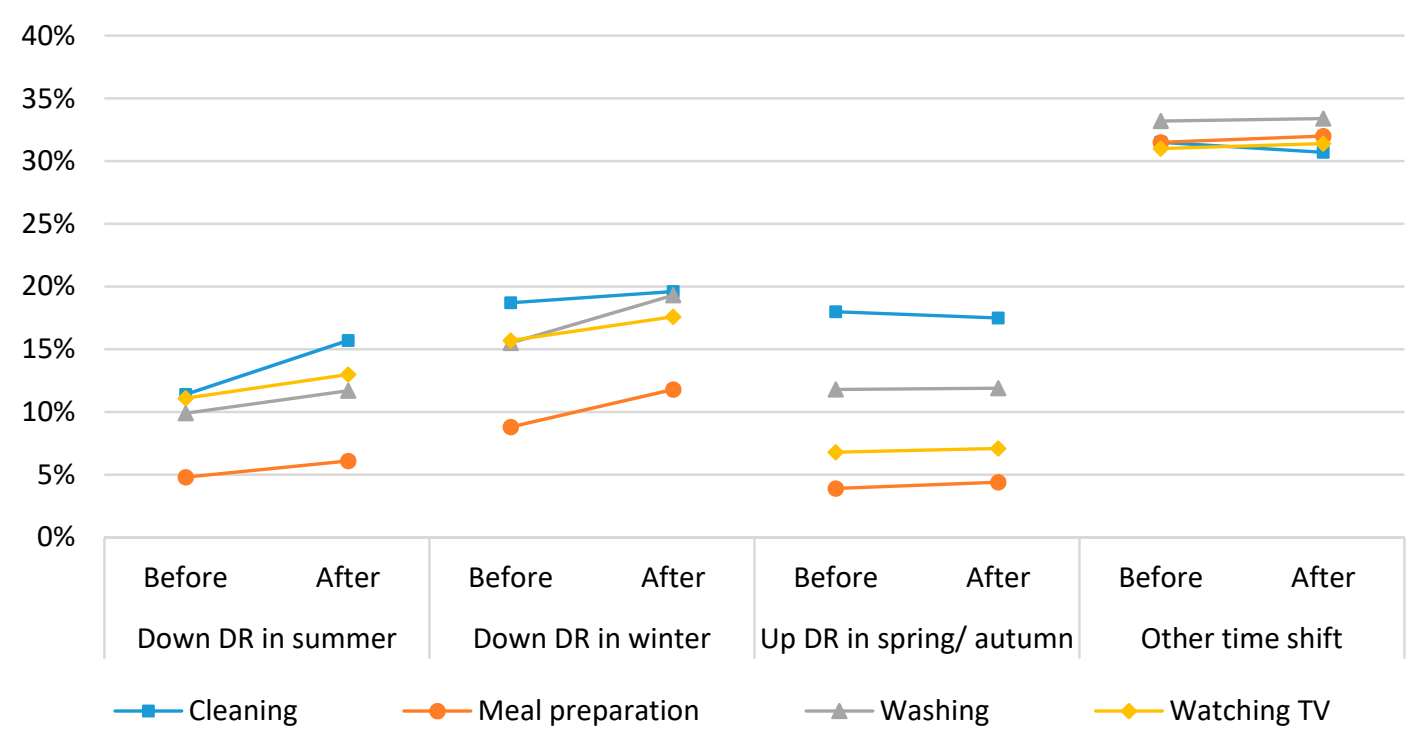

Figure 4. Proportion of respondents who responded to a request for each DR (proportion of all respondents who usually perform each activity).

\subsection{Desired Monthly Reward for Responding to a Request for One of Three Types of DR}

Table 2 shows the average desired monthly reward by household attribute when shifting activity time slots in response to a request for a down DR in summer and winter and a request for up DR in spring/autumn. In the table, italics indicate that the value is relatively high. The higher the desired reward for an activity, the less likely respondents may be to respond to a request for a DR through that activity. According to Table 2, the amount that people desire to receive as a reward for responding to a request for a DR is approximately 500-600 JPY per month. The desired reward for up DR in spring/autumn is slightly lower than that for down DR in summer and winter. This indicates that people are more likely to respond to a request for a DR in spring/autumn than in summer and winter. Looking at the average value of all households and comparing the differences in desired rewards among activities, the desired reward for shifting meal preparation time is highest, followed by the desired reward for washing. Comparing the average rewards among household attributes, households with children, such as households comprising three generations, couples with children, or single parents with children, have a high desired reward. 
Table 2. Desired monthly reward for responding to a request for each of three types of DR (average, unit: JPY).

\begin{tabular}{|c|c|c|c|c|c|c|c|c|}
\hline & $\begin{array}{l}\text { Household } \\
\text { Attributes }\end{array}$ & All & $\begin{array}{l}\text { Single } \\
\text { (Male) }\end{array}$ & $\begin{array}{c}\text { Single } \\
\text { (Female) }\end{array}$ & Couple & $\begin{array}{l}\text { Couple with } \\
\text { Children }\end{array}$ & $\begin{array}{l}\text { Single Parent } \\
\text { with Children }\end{array}$ & $\begin{array}{c}\text { Three } \\
\text { Generations }\end{array}$ \\
\hline \multirow{4}{*}{$\begin{array}{l}\text { Down DR in } \\
\text { summer }\end{array}$} & Cleaning & 561 & 591 & 510 & 552 & 595 & 525 & 534 \\
\hline & Meal preparation & 652 & 708 & 605 & 603 & 697 & 626 & 623 \\
\hline & Washing & 593 & 596 & 537 & 603 & 615 & 603 & 550 \\
\hline & Watching TV & 555 & 626 & 574 & 551 & 519 & 603 & 631 \\
\hline \multirow{2}{*}{$\begin{array}{l}\text { Down DR in } \\
\text { winter }\end{array}$} & Cleaning & 555 & 507 & 561 & 513 & 599 & 572 & 525 \\
\hline & Watching TV & 565 & 558 & 572 & 554 & 552 & 637 & 606 \\
\hline \multirow{4}{*}{$\begin{array}{l}\text { Up DR in } \\
\text { spring/ } \\
\text { autumn }\end{array}$} & Cleaning & 520 & 528 & 517 & 472 & 565 & 509 & 505 \\
\hline & Meal preparation & 610 & 580 & 600 & 560 & 633 & 703 & 656 \\
\hline & Washing & 559 & 559 & 545 & 589 & 500 & 609 & 536 \\
\hline & Watching TV & 528 & 528 & 541 & 536 & 521 & 506 & 604 \\
\hline
\end{tabular}

Italics indicate that the value is relatively high.

\subsection{Factors That Affect the Monthly Desired Reward for DR}

In the previous section, we classified the number of respondents who responded to a request for a $\mathrm{DR}$ in summer, winter, and spring/autumn by eight categories of presented rewards. The presented reward is the desired reward required to respond to a request for a DR for those who have selected the choice that indicates the presented reward. To analyze how a respondent's desired reward is affected by his/her information-gathering behavior, energy-saving consciousness, and demographic factors, we performed an ordered probit analysis (4) using the desired reward as an explained variable $p_{c}$ and the factors that affect it as explanatory variables $x_{i} . p_{c}^{\prime}$ is a latent variable of $p_{c}$.

$$
p_{c}^{\prime}=\alpha_{3}+\sum_{i} \beta_{3 i} x_{i}+u_{3}
$$

Table S3 shows the results of analysis performed using the dataset created after provision of knowledge about the social effectiveness of DR. According to Table S3, the desired reward is significantly lower when the respondent spends more time collecting information on a PC or a similar device and has an energy-saving consciousness or perceives that the DSM is effective. In other words, respondents with such characteristics tend to respond to a request for a DR even with small rewards. Conversely, if the respondent pays a lot of utility bills, is working, lives in a big city, or is older, the desired reward is significantly high. In other words, respondents with such attributes require high rewards to respond to a request for a DR.

Given that a respondent has a low desired reward when he/she easily responds to a request for a DR, and that a respondent has a high desired reward when he/she has difficulty responding to a request for a DR, these results can be interpreted as follows: Perceived effectiveness of DSM is expected to reduce desired rewards and improve responsiveness to a request for a DR. It is also desirable to design a DR program so that those who desire high rewards (i.e., those who are struggling to respond to a request for a DR) are more likely to respond to a request for a DR. According to the above results, those who struggle to respond to a request for a DR are those who pay a lot of utility bills, are working, live in a large city, or are old. It would also be desirable to promote technological development (such as automatic control of home appliances) so that those people could respond to a request for a DR more easily.

\section{Estimation of Response Probability to a Request for a DR under the Given Presented Reward}

Using the estimation results of the binomial logit model described in Section 4.4, we estimated the response probability to a request for a DR under a given presented reward. First, using a model in which response probability is determined only by the presented reward (a model where the utility 
difference function is formulated by Equation (2)), we compared the calculation results of response probabilities before and after providing knowledge about the social effectiveness of DR. Next, using a model in which the response probability is affected by the shift term of the respondents' perceived effectiveness of DR in addition to the presented reward (a model where the utility difference function is formulated by Equation (3)), we examined the effect of respondents' perceived effectiveness of DR on their response probability. We report the estimation results of response probabilities using the two models in the following sections.

\subsection{Comparison of Response Probabilities before and after Providing Knowledge about DR Effectiveness}

Figure 5 shows the results of analysis using a model in which the response probability is determined only by the presented reward (model where the utility difference function is formulated by Equation (2)). It compares response probabilities to a request for a DR before and after providing knowledge about the social effectiveness of DR. The elasticity of response was calculated as the change in response probability when the presented reward changed in the vicinity of the average desired reward. In other words, according to Table 2, the average desired reward for shifting activity time slots is 500-700 JPY; hence, we calculated elasticity of response to a request for a DR when the presented reward changed from 500 to 700 JPY. This price range corresponds to the desired reward when the response probability resulting from the binomial logit model in Section 4.4 is approximately $50 \%$. It is considered that the smaller this value, the more stable the response is to a request for a DR with respect to reward fluctuations. According to Figure 5, after providing knowledge about the social effectiveness of DR, the elasticity of response decreases and responsiveness to a request for a DR against fluctuations in reward becomes stable.

With a presented reward of $50 \mathrm{JPY} /$ month, the response probability to a request for a DR is approximately $30 \%$, while it is approximately $80 \%$ with a reward of $1000 \mathrm{JPY} / \mathrm{month}$. Comparing the response probabilities of the four activities, the response probabilities of meal preparation are relatively low. Comparing response probabilities to a request for a DR in the three seasons, the response probabilities to a request for an up DR in spring/autumn are relatively high. It is apparent that it is relatively easy to influence behavioral changes in shifting activities that were performed in other time slots to the time slot 10:00-14:00, as assumed in DR in spring/autumn. Moreover, the response probability to a request for a DR increases after providing knowledge about the social effectiveness of DR. 


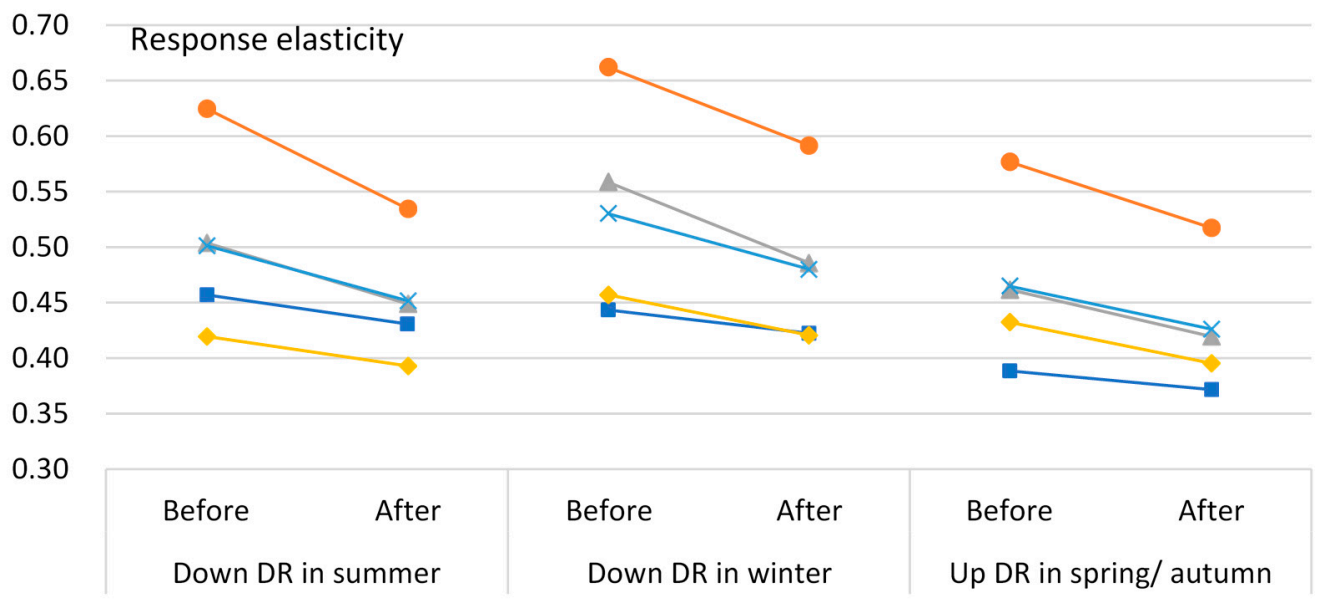

$\rightarrow$ Cleaning $\rightarrow-$ Meal preparation $\rightarrow$ Washing $\longrightarrow$ Watching TV $\leftarrow$ Average of all activities

0.45 Response probability when the presented reward is $50 \mathrm{JPY} /$ month

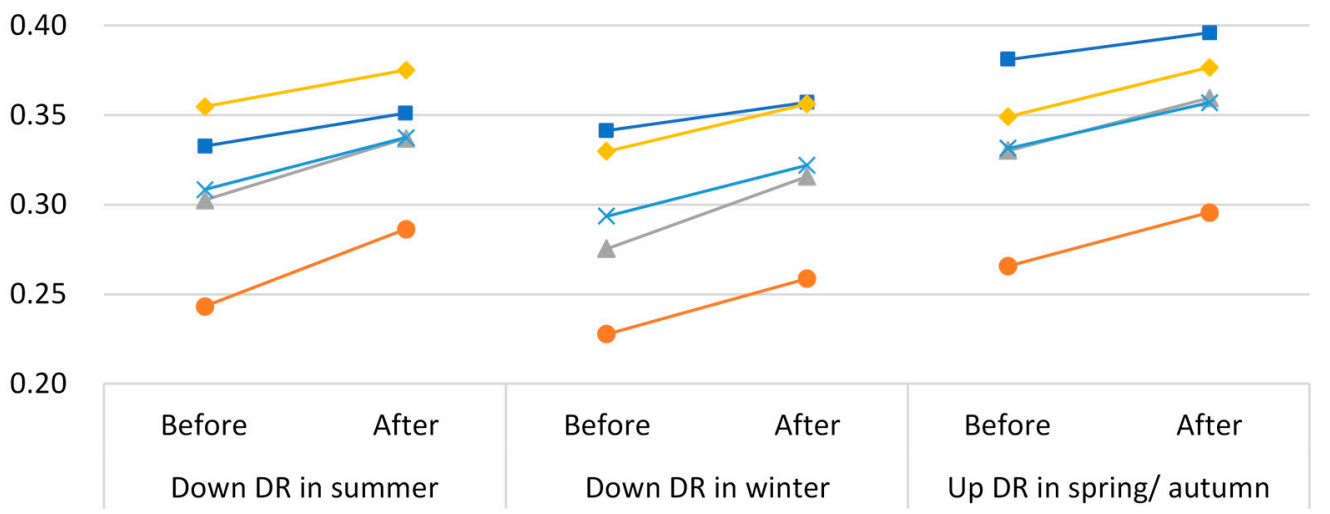

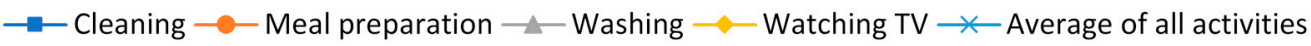

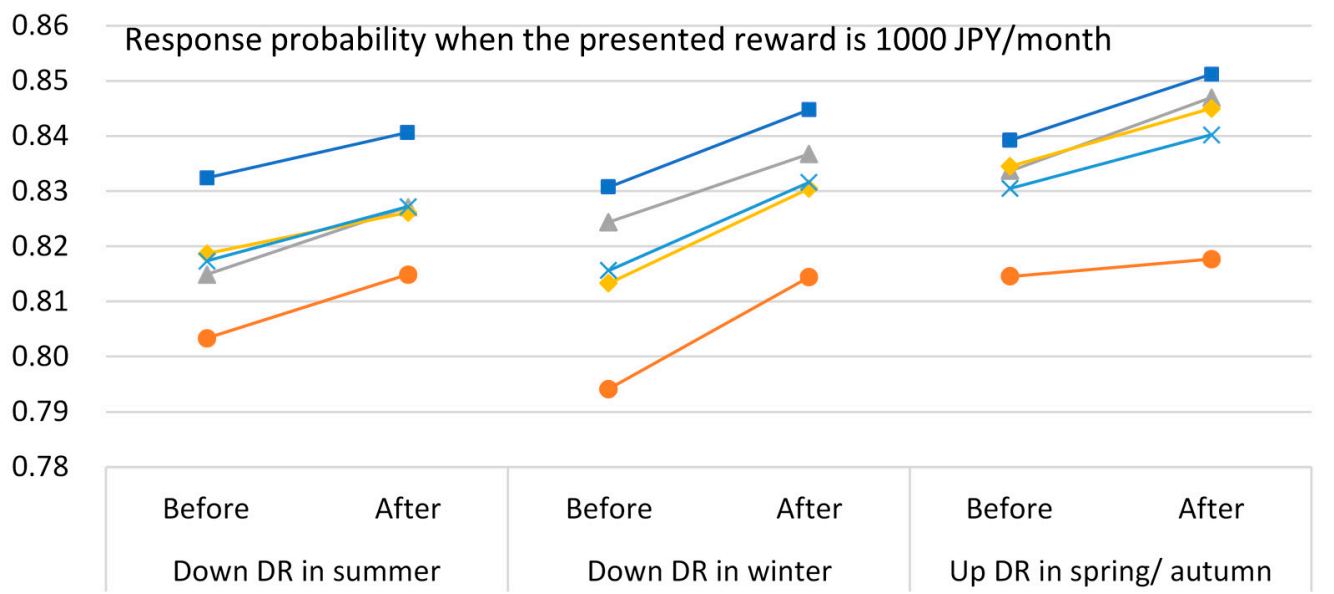

Figure 5. Effect of providing knowledge about DR effectiveness on response probability (comparison before and after providing knowledge).

6.2. Comparison of Response Probability with and without Respondents' Perceived Effectiveness of DR

Figure 6 shows the results of an analysis using a model in which the response probability to a request for a DR is determined by the presented reward and the shift term of respondents' 
perceived effectiveness of DR (a model in which the utility difference function is formulated by Equation (3)). Figure 6 compares response probabilities when dummy $=0$ (without respondents' perceived effectiveness of DR) and dummy $=1$ (with respondents' perceived effectiveness of DR), which indicates the shift term. The results show that when the respondents perceive effectiveness of DR, responsiveness a request for a DR stabilizes against fluctuations in reward and the response probability for the same reward increases with few exceptions.
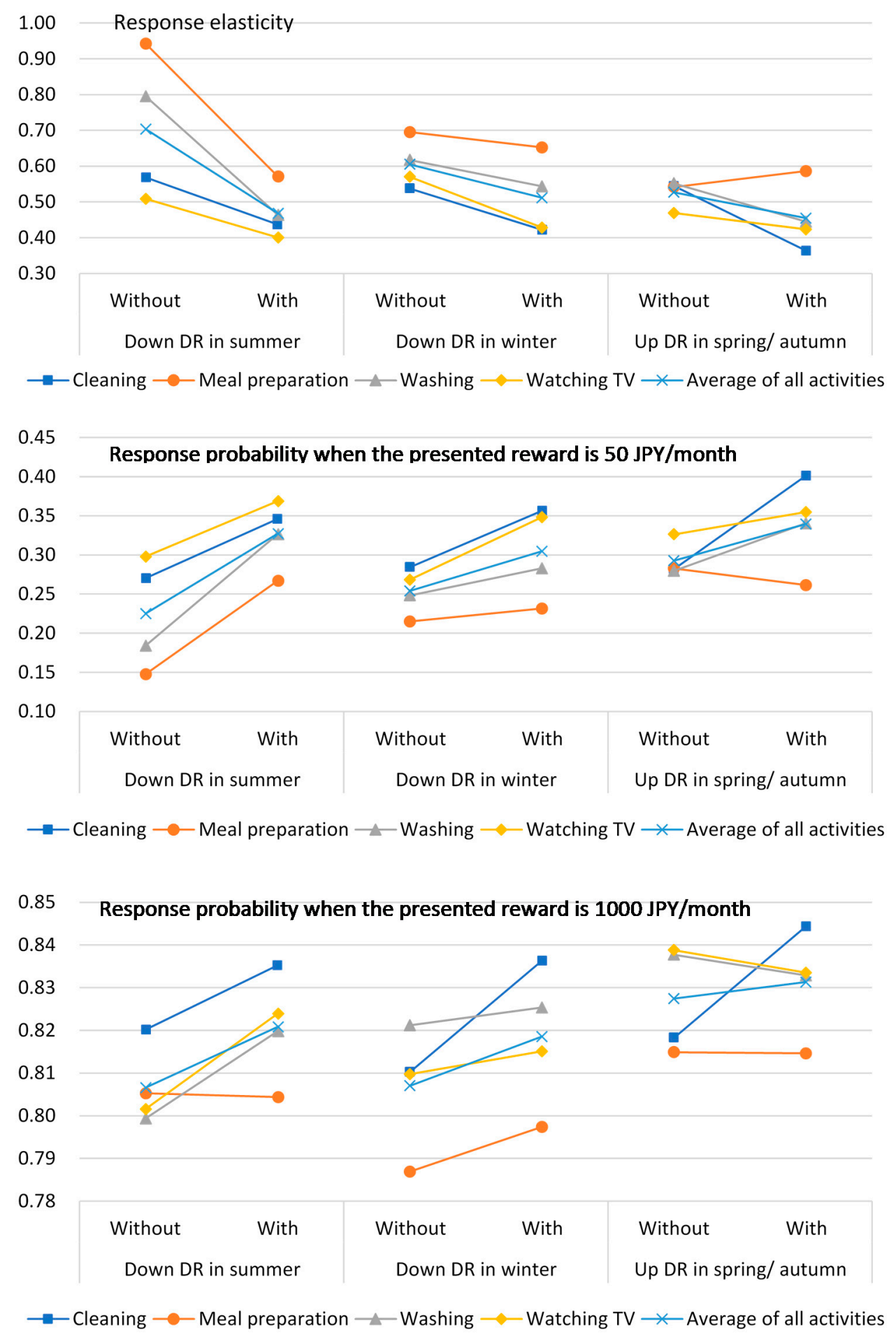

Figure 6. Effect of respondents' perceived effectiveness of DR on response probability (comparison with and without the perceived effectiveness of DR before providing knowledge about DR effectiveness). 


\subsection{Desired Reward Per Unit Electricity for Responding to a Request for a DR}

In the questionnaire, we presented the desired reward in monthly amounts so that the respondents could easily understand the reward system. Table 3 examines the relationship between monthly reward for the three types of DR and the price of adjustable electricity per unit of physical quantity (JPY/kWh). The results in Table 3 are calculated as follows: First, we estimate the monthly adjustable electricity $E_{i}^{K R}$ procured from the time shift of the $i$ th activity under the presented reward of $R \mathrm{JPY} / \mathrm{month}$ for the $K$-type DR as

$$
E_{i}^{K R}=e_{i} \cdot D_{i} \cdot \text { Aprob }_{i}^{K} \cdot \operatorname{Rprob}_{i}^{K R} \quad(\mathrm{kWh} / \mathrm{month})
$$

where $e_{i}$ is the electricity intensity per minute that can be adjusted by shifting the $i$ th activity time slots $(\mathrm{kWh} / \mathrm{min}), D_{i}$ is the monthly duration of the ith activity (min/month), Aprob ${ }_{i}^{K}$ is the average action probability of the $i$ th activity during target time slots of $K$-type DR, $R p r o b_{i}^{K R}$ is the response probability to a request for a DR by $i$ th activity time shift under monthly reward $R$ in $K$-type DR. Here,

$$
\begin{aligned}
& K=\mathrm{DR} \text { in summer, } \mathrm{DR} \text { in winter, and } \mathrm{DR} \text { in spring/autumn } \\
& \qquad R=50,150, \ldots, 1000 \mathrm{JPY} / \mathrm{month} \\
& i=\text { cleaning, preparing meals, washing, and watching } \mathrm{TV}
\end{aligned}
$$

\begin{tabular}{|c|c|c|c|c|c|c|c|c|}
\hline & $\begin{array}{c}\text { Presented } \\
\text { Monthly Reward }\end{array}$ & $50 \mathrm{JPY}$ & $150 \mathrm{JPY}$ & $300 \mathrm{JPY}$ & $500 \mathrm{JPY}$ & $700 \mathrm{JPY}$ & $900 \mathrm{JPY}$ & $1000 \mathrm{JPY}$ \\
\hline \multirow{3}{*}{$\begin{array}{c}\text { Before } \\
\text { providing } \\
\text { knowledge }\end{array}$} & $\begin{array}{l}\text { Down DR in } \\
\text { summer }\end{array}$ & 20.29 & 50.47 & 78.69 & 99.38 & 112.60 & 124.50 & 130.82 \\
\hline & $\begin{array}{l}\text { Down DR in } \\
\text { winter }\end{array}$ & 10.71 & 26.40 & 40.61 & 50.42 & 56.32 & 61.63 & 64.50 \\
\hline & $\begin{array}{l}\text { Up DR in } \\
\text { spring/autumn }\end{array}$ & 15.77 & 39.48 & 62.18 & 79.59 & 91.27 & 101.86 & 107.42 \\
\hline \multirow{3}{*}{$\begin{array}{c}\text { After } \\
\text { providing } \\
\text { knowledge }\end{array}$} & $\begin{array}{l}\text { Down DR in } \\
\text { summer }\end{array}$ & 17.64 & 44.69 & 71.58 & 93.34 & 108.48 & 122.07 & 129.06 \\
\hline & $\begin{array}{l}\text { Down DR in } \\
\text { winter }\end{array}$ & 9.50 & 23.68 & 37.05 & 47.08 & 53.71 & 59.75 & 62.95 \\
\hline & $\begin{array}{l}\text { Up DR in } \\
\text { spring/autumn }\end{array}$ & 14.28 & 36.28 & 58.37 & 76.55 & 89.38 & 100.93 & 106.85 \\
\hline
\end{tabular}

Table 3. Relationship between presented monthly reward and electricity price of adjusting power (Unit: JPY/kWh).

This table is calculated using the following assumptions: Monthly duration of each activity: Cleaning, $225 \mathrm{~min}$ (15 min $\times 15$ times); meal preparation, $1800 \mathrm{~min}$ (30 $\mathrm{min} \times 60$ times); washing $450 \mathrm{~min}$ (30 $\mathrm{min} \times 15$ times); watching TV, $1800 \mathrm{~min}$ (60 $\mathrm{min} \times 30$ times). Power saved by discontinuing use of home appliances [6]: cleaning, $317.8 \mathrm{Wh} / 15 \mathrm{~min}$; meal preparation $474.9 \mathrm{Wh} / 15 \mathrm{~min}$; washing, $96.8 \mathrm{Wh} / 15 \mathrm{~min}$; watching TV, $24.9 \mathrm{Wh} / 15 \mathrm{~min}$.

Under the monthly presented reward $R$ (JPY/month) during target time slots of K-type DR, the total adjustable electricity $T E^{K R}$ by four activities per month is calculated as follows:

$$
T E^{K R}=\sum_{i} E_{i}^{T K}(\mathrm{kWh} / \mathrm{month})
$$

By dividing the monthly presented reward R (JPY/month) by $T E^{K R}$, the price of adjustable electricity $P E^{K R}$ procured by the $K$-type DR under the presented reward of $R$ JPY per month can be calculated as follows:

$$
P E^{K R}=\frac{R}{\sum_{i} E_{i}^{T K}}(\mathrm{JPY} / \mathrm{kWh})
$$

Table 3 lists the calculation results of $P E^{K R}$. The electricity intensity per minute, $e_{i}$, and the monthly duration, $D_{i}$, of each activity in Equation (5) are shown in the footnotes of Table 3. For the average action probability of each activity during target time slots of $K$-type DR $A p r o b_{i}^{K}$, we applied 
the results for the average of all households in Section 5.1. Here, the value for down DR in summer and winter is the average action probability in all time slots of each down DR, and the value for up DR in spring/autumn is the average action probability in all time slots other than the time slots of the up DR. The estimation results in Section 6.1 were applied to the response probability to a request for a DR $\operatorname{Rprob}_{i}^{K R}$ of each activity according to each presented reward.

Looking at the actual price of adjustable electricity in Japan, the weighted average of all electric power companies for each week in 2018 is $10.4 \mathrm{JPY} / \mathrm{kWh}$ in the case of up DR and 7.5 JPY/kWh in the case of down DR. The weighted average of up and down DR is $8.9 \mathrm{JPY} / \mathrm{kWh}$ [34]. Comparing these actual prices with the calculated price in Table 3, it can be seen that the calculated price is considerably higher than the actual price. Even if it is assumed that the price of adjustable electricity will slightly increase in the near future and will be 10-20 JPY/kWh, a reasonable monthly reward is approximately $50 \mathrm{JPY} / \mathrm{month}$ for each DR. Therefore, if the price of the adjustable electricity market in Japan changes to approximately 10-20 JPY/kWh, only those who have a low desired reward of $50 \mathrm{JPY} / \mathrm{month}$ are eligible for DR.

\subsection{Estimating Adjustable Electricity by Time of Day}

Nakano and Washizu [6] used STU to estimate the maximum amount of electricity that can be adjusted according to behavioral changes of Japanese people by time of day. In this section, by multiplying the adjustable electricity potential estimated by Nakano and Washizu [6] by the response probability to a request for a DR revealed in this research, we estimate the amount of electricity that will become available during DR out of the potential adjustable electricity.

The column "Electricity subject to DR" in Table 4 shows the achievable adjustable electricity, excluding the electricity consumption by people who do not shift their activity time slots from the maximum adjustable electricity estimated by Nakano and Washizu [6]. This can be interpreted as the potential electricity that is subject to DR. Looking at the total amount of achievable adjustable electricity estimated for the four activities, for example, the total that is subject to down DR from 8:00-16:00 is 34.6 GWh during summer, before providing knowledge about the social effectiveness of DR. However, the value rises to 36.6 GWh after providing this knowledge. This is $25-27 \%$ of the value estimated by Nakano and Washizu [6] as total electricity consumption by household appliances used in the time slot 8:00-16:00 in Japanese households.

The numbers in the four columns on the right side of Table 4 are estimated values of adjustable electricity procured in DR when the people's response probability to a request for a DR is taken into consideration. The reward assumed here is equivalent to the electricity price in the electricity adjustment market of 10-20 JPY/kWh. According to the considerations discussed in Section 6.3, assuming that the price of adjustable electricity is 10-20 JPY/kWh, a reasonable monthly reward is approximately $50 \mathrm{JPY} / \mathrm{month}$ for each DR. Looking at the down DR from 8:00-16:00 in summer, the total amount of adjustable electricity procured from the four activities under the price would be $10.6 \mathrm{GWh}$ before providing knowledge about the social effectiveness of DR. However, the value rises to $12.2 \mathrm{GWh}$ after providing this knowledge, which is equivalent to $8-9 \%$ of the total electricity consumption by household appliances from 8:00-16:00 in Japanese households estimated by Nakano and Washizu [6]. Looking at the down DR in winter, the ratio is approximately $4-6 \%$.

Adjustable electricity for up DR in spring/autumn is procured by shifting people's current activity time slots scattered across times outside the 10:00-14:00 period, which is the target time for DR in spring/autumn, into the desired time period. The adjustable electricity is $28.7 \mathrm{GWh}$ before provision of knowledge on the effectiveness of DR and 33.2 GWh after provision. Since activities in many time slots are subject to shifts, a relatively large amount of adjustable electricity can be expected even under a low reward of $50 \mathrm{JPY} / \mathrm{month}$ and thus with a low response probability to a request for a DR. The adjustable electricity is almost equal to the power consumption by home appliances in 10:00-14:00 (100-115\%). In the 10:00-14:00 time slot power consumption of households is relatively low. The aforementioned results show that adjustable electricity has considerable importance in the time slots when power 
consumption is relatively low. It can be concluded that the implementation effect of DSM is most significant during these time slots.

Table 4. Estimated result of adjustable electricity by time of day (Unit: GWh, excluding items with \%).

\begin{tabular}{|c|c|c|c|c|c|c|c|c|c|}
\hline \multirow{4}{*}{\multicolumn{2}{|c|}{ Time Slots }} & \multicolumn{4}{|c|}{ Electricity Subject to DR *2 } & \multicolumn{4}{|c|}{$\begin{array}{l}\text { Adjusted Electricity under the Monthly } \\
\text { Reward of } 50 \mathrm{JPY} * 3\end{array}$} \\
\hline & & \multicolumn{3}{|c|}{ Down DR } & \multirow{3}{*}{$\begin{array}{c}\begin{array}{c}\text { Up DR } \\
\text { in } \\
\text { Spring/Autumn }\end{array} \\
\text { 10-14 }\end{array}$} & \multicolumn{3}{|c|}{ Down DR } & \multirow{3}{*}{$\begin{array}{c}\text { Up DR } \\
\text { in Spring } \\
\text { Autumn } \\
10-14\end{array}$} \\
\hline & & \multirow{2}{*}{$\begin{array}{c}\begin{array}{c}\text { in } \\
\text { Summer }\end{array} \\
8-16\end{array}$} & \multicolumn{2}{|c|}{ in Winter } & & \multirow{2}{*}{$\begin{array}{c}\text { in } \\
\text { Summer }\end{array}$} & \multicolumn{2}{|c|}{ in Winter } & \\
\hline & & & $6-10$ & $16-22$ & & & $6-10$ & $16-22$ & \\
\hline \multirow{6}{*}{$\begin{array}{c}\text { Before } \\
\text { providing } \\
\text { knowledge }\end{array}$} & Cleaning & 19.1 & 14.7 & 5.5 & 23.4 & 6.4 & 5.0 & 1.9 & 8.9 \\
\hline & Meal preparation & 9.7 & 14.6 & 32.1 & 52.5 & 2.4 & 3.3 & 7.3 & 13.9 \\
\hline & Washing & 2.3 & 3.2 & 0.5 & 4.2 & 0.7 & 0.9 & 0.1 & 1.4 \\
\hline & Watching TV & 3.4 & 1.4 & 7.7 & 12.8 & 1.2 & 0.5 & 2.5 & 4.5 \\
\hline & Total & 34.6 & 34.0 & 45.8 & 92.8 & 10.6 & 9.7 & 11.9 & 28.7 \\
\hline & $\left(\right.$ Proportion $\left.{ }^{* 1}\right)$ & $(25.3 \%)$ & $(17.9 \%)$ & $(13.9 \%)$ & $(323.5 \%)$ & $(7.8 \%)$ & $(5.1 \%)$ & $(3.6 \%)$ & $(100.0 \%)$ \\
\hline \multirow{6}{*}{$\begin{array}{c}\text { After } \\
\text { providing } \\
\text { knowledge }\end{array}$} & Cleaning & 20.0 & 15.4 & 5.8 & 24.5 & 7.0 & 5.5 & 2.1 & 9.7 \\
\hline & Meal preparation & 10.6 & 15.9 & 34.8 & 56.9 & 3.0 & 4.1 & 9.0 & 16.8 \\
\hline & Washing & 2.5 & 3.5 & 0.5 & 4.5 & 0.8 & 1.1 & 0.2 & 1.6 \\
\hline & Watching TV & 3.5 & 1.5 & 8.1 & 13.4 & 1.3 & 0.5 & 2.9 & 5.1 \\
\hline & Total & 36.6 & 36.2 & 49.2 & 99.3 & 12.2 & 11.2 & 14.1 & 33.2 \\
\hline & $\left(\right.$ Proportion $\left.{ }^{* 1}\right)$ & $(26.8 \%)$ & $(19.1 \%)$ & $(14.9 \%)$ & $(346.0 \%)$ & $(8.9 \%)$ & $(5.9 \%)$ & $(4.3 \%)$ & $(115.6 \%)$ \\
\hline
\end{tabular}

$* 1$ Ratio of the above value to the electricity usage in the corresponding time slots. ${ }^{* 2}$ A value that excludes the amount of electricity used by people who cannot shift their activity time slots from the total amount of potential electricity subject to adjustment. In other words, the amount of potential electricity that can be realized by DR.

$* 3$ Reward equivalent when the electricity price in the electricity adjustment market is $10-20 \mathrm{JPY} / \mathrm{kWh}$.

\section{Discussion}

With the improvement in the introduction of fluctuating renewable energies, such as photovoltaics (PVs), DSM based on consumers sharing a power supply and demand adjustment has received considerable attention. Previous studies have revealed that such discussions are becoming more active, particularly in large cities in developed countries, where diverse DERs are being abundantly installed. Public participation is a key factor determining the effectiveness of new sustainable energy systems, including DSM; therefore, considerations of the conditions of public participation are actively being studied in large cities in developed countries.

In this study, we conducted a questionnaire survey of 10,000 households in Japan. We investigated the proportion of people responding to a request for a DR under the given presented reward in time slots when DSM by DR is required. We also analyzed the factors influencing people's response to a request for a DR. Furthermore, under a certain reward, we estimated how much adjustable power would be realized among the potential electricity subject to DR, that is, maximum adjustable electricity, estimated by Nakano and Washizu [6].

We investigated people's responsiveness to a request for a DR by shifting the time slots of four types of activities: cleaning, meal preparation, washing, and watching TV. The percentage of those who cannot shift their current activity time slots, i.e., the percentage of those who cannot respond to a request for a DR, among people who usually engage in each activity is as follows: approximately $40 \%$ of people cannot shift their current meal preparation time slots, approximately $30 \%$ cannot shift watching TV time slots, and approximately $20 \%$ cannot shift washing or cleaning time slots. Providing knowledge about the social effectiveness of DR reduces these rates. It also increases the proportion of people who respond to shifts in their activity time slots and respond to a request for a DR.

People's desired monthly reward for responding to a request for a down DR in spring/autumn is lower than that desired to up DR in summer and winter. This shows that people are more likely to respond to a request for an up DR in spring/autumn than down DR in summer and winter. People's desired reward for time shift of meal preparation is the highest, followed by the desired reward 
for time shift of washing. Comparing household attributes, the desired reward is highest in households with children. A higher desired reward would mean less responsiveness to the associated DR.

Using an ordered probit model, we analyzed the factors that influence the desired reward for responding to a request for a DR. According to the results, the desired reward is significantly lower when a respondent perceives the effectiveness of the DSM. On the other hand, if a respondent pays a lot of utility bills, is working, lives in a big city, or is older, the desired reward is significantly higher. These results suggest that knowledge of the effectiveness of DSM is expected to reduce desired rewards and improve responsiveness to a request for a DR. It is also desirable to design a DR program so that those who desire high rewards (i.e., those who are reluctant to respond to a request for a DR) are more likely to respond to a request for a DR. It would also be desirable to promote technological development (such as automatic control of home appliances) so that those people could respond to a request for a DR more easily.

Using the estimation results of a binomial logit model, we estimated the response probability to a request for a DR under a given presented reward. Comparing response probabilities to a request for a DR before and after providing knowledge about the social effectiveness of DR, the change in response probability with respect to the change in reward stabilizes; the response probability to the same presented reward increases after providing this knowledge. The response probability to a request for a DR is approximately $30 \%$ under the presented reward of $50 \mathrm{JPY} /$ month and approximately $80 \%$ under the reward of $1000 \mathrm{JPY} /$ month. The probability of responding to a request for a DR by shifting meal preparation time slots is relatively low, and the response probability to a request for an up DR in spring/autumn is relatively high. People seem to have difficulty responding to shifting meal preparation time slots; it may be easier for people to engage in behavioral change of shifting activities performed in other time slots to the time slot 10:00-14:00. When people perceive the effectiveness of DR, the change in response probability with respect to the change in reward stabilizes, and the response probability to the same presented reward increases. This suggests the importance of educating people about the effectiveness of DR.

In the questionnaire, we presented the desired reward in monthly amounts so that the respondents could easily understand the reward system. We examined the relationship between the monthly reward and the price per $1 \mathrm{kWh}$ of adjustable electricity procured by the DR. It was estimated that $10-20 \mathrm{JPY} / \mathrm{kWh}$, which is the actual price of adjustable electricity currently traded in Japan, corresponds to a low monthly reward of $50 \mathrm{JPY} / \mathrm{month}$. Therefore, in the near future, if the price of the adjustable electricity market in Japan changes to approximately 10-20 JPY/kWh, only those who have a low desired reward of $50 \mathrm{JPY} /$ month are eligible for DR. We calculated the amount that actually appears as adjustable power through DR by multiplying the potential adjustable power estimated by Nakano and Washizu [6] by the response probability to a request for a DR revealed in this study. As a result, when the price of adjustable electricity is $10-20 \mathrm{JPY} / \mathrm{kWh}$, during the time slots when down DR is required in summer, approximately $8-9 \%$ of total electricity consumption can be procured through DR as adjustable electricity. During time slots when down DR is required in winter, $4-6 \%$ of total electricity consumption can be procured as adjustable electricity. Conversely, during the time slots when up $\mathrm{DR}$ is required in spring/autumn, even when the price of adjustable electricity is 10-20 JPY/kWh, the amount of adjustable electricity procured through DR is approximately the same as the total electricity consumption. This result shows that adjustable electricity has considerable importance in the spring/autumn daytime slots when power consumption is relatively low. It would be desirable for the DR program to be implemented at such time slots.

In this study, we combined the results of a new questionnaire survey with the potential adjustable electricity that can contribute to DSM, as estimated based on official statistics by Nakano and Washizu [6]. Then, we estimated the adjustable electricity that could realistically be procured by the DR at the macrolevel. In order to find an effective method for implementing DSM, it is important to analyze the trend of society as a whole by using public statistics surveyed on a large scale under an unbiased 
sample design. Our results, which are based on official statistics, are important for verifying the effectiveness of DSM from a macroscopic perspective.

\section{Conclusions}

Under effective DSM that uses the latest IoT to maximize the use of renewable energy, we believe that sparing use of appliances is not the only solution to address global warming. If behavioral change shifts the use of domestic appliances from one time slot to other time slots, we do not have to abandon the use of these appliances. To that end, we conducted a questionnaire-based survey of 10,000 households in Japan. We investigated the proportion of people responding to a request for a demand response (DR) under the given presented reward in time slots when DSM by DR is required.

We also analyzed the factors influencing people's response to a request for a DR. Furthermore, under a certain reward, we estimated how much adjustable power would be realized among the potential electricity subject to DR, i.e., maximum adjustable electricity. Under the actual price of adjustable electricity of 10-20 JPY/kWh, during the time slots when "down DR" (a reduction of electricity demand) is required in summer, approximately $8-9 \%$ of total electricity consumption can be procured through DR as adjustable electricity. During time slots when down DR is required in winter, approximately $4-6 \%$ of total electricity consumption can be procured as adjustable electricity. During the time slots when "up DR" (an increase of electricity demand) is required in spring/autumn, the amount of adjustable electricity that can be procured through DR is approximately the same as the total electricity consumption. Further, after providing knowledge about the social effectiveness of DR, the adjustable electricity that can be procured through DR increases. When people perceive the effectiveness of DR, the response probability to the same presented reward increases.

The aim of our study was to determine the possibility of such behavioral changes in people in order to provide basic information for operating an effective DSM. In Japan, the reform and design of a new system in the electricity market, including the adjustment market, is currently in progress. In future research, we will consider the relationship between the direction of these changes and the observational facts obtained in this study. In addition, verification of the effects of various technological developments for realizing improved DSM and determination of the direction of technological developments are issues to be addressed in further research.

Supplementary Materials: The following are available online at http://www.mdpi.com/1996-1073/13/14/3665/s1, Table S1: Results of logit analysis: response probability to a request for a DR (before providing knowledge about the effectiveness of DR), Table S2: Results of logit analysis: response probability to a request for a DR (after providing knowledge about the effectiveness of DR), Table S3 Results of ordered probit analysis: factors affecting desired reward (after providing knowledge of DR effectiveness).

Author Contributions: Conceptualization, all; methodology, all; software, S.N.; validation, all; formal analysis, all; investigation, all; resources, all; data curation, all; writing — original draft preparation, A.W.; writing-review \& editing, all; visualization, all; supervision, all; project administration, A.W.; funding acquisition, A.W. All authors have read and agreed to the published version of the manuscript.

Funding: This study was funded by a MEXT Grant-in-Aid of Scientific Research (19KT0037), a Waseda University Grant for Special Research Projects (2020C-344), the Environment Research and Technology Development Fund (JPMEERF20202008) of MOE and the Environmental Restoration and Conservation Agency of Japan.

Acknowledgments: This research was approved by the Ethics Review Committee on Research with Human Subjects of Waseda University (Application No. 2019-002).

Conflicts of Interest: The authors declare no conflict of interest.

\section{References}

1. Statistics Bureau of Japan, Housing and Land Survey. Available online: https://www.e-stat.go.jp/en/statsearch/files?page $=1 \&$ toukei=00200522\&tstat=000001127155 (accessed on 1 May 2020). 
2. Agency for Natural Resources and Energy (ANRE). 16th Advisory Committee for Natural Resources and Energy Conservation/New Energy Subcommittee/Electricity and Gas Business Subcommittee/Renewable Energy Mass Introduction and Next Generation Electricity Network Subcommittee Material 2. 2019; (in Japanese). Available online: https://www.meti.go.jp/shingikai/enecho/denryoku_gas/saisei_kano/016.html (accessed on 1 May 2020).

3. Heat Pump \& Thermal Storage Technology Center of Japan (HPTCJ) Web Page. Available online: https://www.hptcj.or.jp/individual/tabid/149/Default.aspx (accessed on 1 May 2020).

4. Dao, V.T.; Ishii, H.; Takenobu, Y.; Yoshizawa, S.; Hayashi, Y. Intensive quadratic programming approach for home energy management systems with power utility requirements. Int. J. Electr. Power Energy Syst. 2020, 115, 105473. [CrossRef]

5. Baba, H.; Saito, T.; Kataoka, K.; Iwafune, Y.; Ogimoto, K.; Udagawa, Y.; Amatsu, T.; Masuda, H. Demand response with utilizing IoT for mitigation of curtailment at over-generation of VRE. IEEJ Trans. Electron. Inf. Syst. 2017, 137, 326-332. [CrossRef]

6. Nakano, S.; Washizu, A. In which time slots can people save power? An analysis using a Japanese survey on time use. Sustainability 2019, 11, 4444. [CrossRef]

7. Büscher, C.; Sumpf, P. "Trust" and "confidence" as socio-technical problems in the transformation of energy systems. Energy Sustain. Soc. 2015, 5, 1-13. [CrossRef]

8. Soland, M.; Loosli, S.; Koch, J.; Christ, O. Acceptance among residential electricity consumers regarding scenarios of a transformed energy system in Switzerland-A focus group study. Energy Effic. 2018, 11, 1673-1688. [CrossRef]

9. He, X.; Keyaerts, N.; Azevedo, I.; Meeus, L.; Hancher, L.; Glachant, J.-M. How to engage consumers in demand response: A contract perspective. Util Policy 2013, 27, 108-122. [CrossRef]

10. Stenner, K.; Frederiks, E.R.; Hobman, E.V.; Cook, S. Willingness to participate in direct load control: The role of consumer distrust. Appl. Energy 2017, 189, 76-88. [CrossRef]

11. Good, N. Using behavioural economic theory in modelling of demand response. Appl. Energ 2019, 239, 107-116. [CrossRef]

12. Pratt, B.W.; Erickson, J.D. Defeat the peak: Behavioral insights for electricity demand response program design. Energy Res. Soc. Sci. 2020, 61, 101352. [CrossRef]

13. Siebert, L.C.; Sbicca, A.; Aoki, A.R.; Lambert-Torres, G. A behavioral economics approach to residential electricity consumption. Energies 2017, 10, 768. [CrossRef]

14. Iliopoulos, N.; Esteban, M.; Kudo, S. Assessing the willingness of residential electricity consumers to adopt demand side management and distributed energy resources: A case study on the Japanese market. Energy Policy 2020, 137, 111169. [CrossRef]

15. Washizu, A.; Nakano, S.; Ishii, H.; Hayashi, Y. Willingness to pay for home energy management systems: A survey in New York and Tokyo. Sustainability 2019, 11, 4790. [CrossRef]

16. Roth, L.; Lowitzsch, J.; Yildiz, Ö.; Hashani, A. Does (Co-)ownership in renewables matter for an electricity consumer's demand flexibility? Empirical evidence from Germany. Energy Res. Soc. Sci. 2018, 46, 169-182. [CrossRef]

17. Walzberg, J.; Dandres, T.; Merveille, N.; Cheriet, M.; Samson, R. Accounting for fluctuating demand in the life cycle assessments of residential electricity consumption and demand-side management strategies. J. Clean Prod. 2019, 240, 118251. [CrossRef]

18. Ruokamo, E.; Kopsakangas-Savolainen, M.; Meriläinen, T.; Svento, R. Towards flexible energy demand-Preferences for dynamic contracts, services and emissions reductions. Energy Econ. 2019, 84, 104522. [CrossRef]

19. Sundt, S.; Rehdanz, K.; Meyerhoff, J. Consumers' willingness to accept time-of-use tariffs for shifting electricity demand. Energies 2020, 13, 1895. [CrossRef]

20. Nilsson, A.; Stoll, P.; Brandt, N. Assessing the impact of real-time price visualization on residential electricity consumption, costs, and carbon emissions. Resour. Conserv. Recycl. 2017, 124, 52-161. [CrossRef]

21. Khalilpour, K.R.; Lusis, P. Network capacity charge for sustainability and energy equity: A model-based analysis. Appl. Energy 2020, 266, 114847. [CrossRef]

22. Burton, C.A.; Ryan, C.; Rismanchi, B.; Candy, S. Urban shared energy systems and behaviour change-simulating a common pooled resource problem. Smart Sustain. Built. Environ. 2019, 9, 17-26. [CrossRef] 
23. Lazowski, B.; Parker, P.; Rowlands, I.H. Towards a smart and sustainable residential energy culture: Assessing participant feedback from a long-term smart grid pilot project. Energy Sustain. Soc. 2018, 8, 27. [CrossRef]

24. Ahmed, N.; Levorato, M.; Li, G.P. Residential consumer-centric demand side management. IEEE Trans. Smart Grid. 2018, 9, 4513-4524. [CrossRef]

25. Walzberg, J.; Dandres, T.; Merveille, N.; Cheriet, M.; Samson, R. Should we fear the rebound effect in smart homes? Renew. Sust. Energy Rev. 2020, 125, 109798. [CrossRef]

26. Aryandoust, A.; Lilliestam, J. The potential and usefulness of demand response to provide electricity system services. Appl. Energy 2017, 204, 749-766. [CrossRef]

27. Fischer, D.; Stephen, B.; Flunk, A.; Kreifels, N.; Lindberg, K.B.; Wille-Haussmann, B.; Owens, E.H. Modeling the effects of variable tariffs on domestic electric load profiles by use of occupant behavior submodels. IEEE Trans. Smart Grid 2017, 8, 2685-2693. [CrossRef]

28. Thiaux, Y.; Dang, T.T.; Schmerber, L.; Multon, B.; Ben Ahmed, H.; Bacha, S.; Tran, Q.T. Demand-side management strategy in stand-alone hybrid photovoltaic systems with real-time simulation of stochastic electricity consumption behavior. Appl. Energy 2019, 253, 113530. [CrossRef]

29. Nijhuis, M.; Gibescu, M.; Cobben, J.F.G. Bottom-up Markov chain Monte Carlo approach for scenario based residential load modelling with publicly available data. Energy Build. 2016, 112, 121-129. [CrossRef]

30. Torriti, J. Demand side management for the European Supergrid: Occupancy variances of European single-person households. Energy Policy 2012, 44, 199-206. [CrossRef]

31. López-Rodríguez, M.A.; Santiago, I.; Trillo-Montero, D.; Torriti, J.; Moreno-Munoz, A. Analysis and modeling of active occupancy of the residential sector in Spain: An indicator of residential electricity consumption. Energy Policy 2013, 62, 742-751. [CrossRef]

32. Santiago, I.; Lopez-Rodriguez, M.A.; Trillo-Montero, D.; Torriti, J.; Moreno-Munoz, A. Activities related with electricity consumption in the Spanish residential sector: Variations between days of the week, autonomous communities and size of towns. Energy Build. 2014, 79, 84-97. [CrossRef]

33. McFadden, D. Conditional Logit Analysis of Qualitative Choice Behavior. In Frontiers in Econometrics; Zarembka, P., Ed.; Academic Press: Cambridge, MA, USA, 1974; pp. 105-142.

34. Electricity and Gas Trading Monitoring Committee. Electric Power Price of Adjusting Power Ordered by General Power Transmission and Distribution Companies. 2018. Available online: https://www.emsc.meti. go.jp/info/public/news/20190124001.html (accessed on 1 May 2020).

(C) 2020 by the authors. Licensee MDPI, Basel, Switzerland. This article is an open access article distributed under the terms and conditions of the Creative Commons Attribution (CC BY) license (http://creativecommons.org/licenses/by/4.0/). 